\title{
Desafios para a ação interdisciplinar na atenção básica: implicações relativas à composição das equipes de saúde da família
}

\author{
Challenges to an interdisciplinary action in basic care: \\ implications related to composition of family health teams
}

\author{
Gecioni Loch-N eckel ${ }^{1}$ \\ Giane Seemann ${ }^{1}$ \\ Helena Berton Eidt ${ }^{1}$ \\ Michelli Moroni Rabuske ${ }^{1}$ \\ M aria A parecidaCrepaldi 1,2
}

${ }^{1}$ Departamento deSaúde Pública, Centro deCiências daSaúde, UFSC. Campus

Universitário Trindade.

88040-970 Florianópolis

SC.gneckel@hotmail.com

${ }^{2}$ Departamento de

Psicologia, Centro de

Filosofia e Ciências

Humanas, Universidade

Federal deSanta Catarina.
Abstract The Family H ealth Program emerges as a new strategy of health care as well as a reorientation of the assistance model. Based on these presuppositions, this article reflects on the relationship between integrality in basic care and the composition of family health teams, in the view of the Family $\mathrm{H}$ ealth Program minimum team members, characterizing the possible fields of action and the contributions of other health professionals in the Family H ealth Program. Undergraduates and members of a Family $\mathrm{H}$ ealth Program team from a certain city in the south of Brazil participated in this research. The quality of personal or professional expertise of these professionals contributed to a better understanding of their intervention possibilities. The investigation also allowed the analysis of how the family health strategy has been reaching the members who constitute the minimum teamsat local context. In addition to that, the research highlighted how the integrality and interdisciplinarity have been understood by the teams members, and the relationships between team arrangement and the (im) possibilities of action.

Key words Family Health Team, Integrality, Interdisciplinarity, Basic care
Resumo 0 Programa Saúdeda Família (PSF) surge como uma nova estratégia de atenção à saúde e de reorientação do modelo de assistência. Partindo desses pressupostos, o presente artigo tem como objetivo refletir sobre a relação entre integralidade na atenção básica e a composição das equipes de saúde da família, na perspectiva dos integrantes da equipe mínima do PSF, caracterizando as possibilidades de atuação e contribuições de outros profissionais de saúde no PSF. Participaram da pesquisa profissionais com curso superior, membros de equipes de PSF de um município no sul do Brasil. A qualidade da experiência profissional ou pessoal acerca da atuação desses profissionais contribuiu para o conhecimento sobre suas possibilidades de intervenção. A investigação permitiu também analisar como a estratégia de saúde da família tem atingido os integrantes que constituem as equipes mínimas no contexto local. Além disso, evidenciou de que maneira a integralidade e a interdisciplinaridade têm sido entendidas pelos que compõem tais equipes, e as relações entre a composição das equipes e as (im) possibilidades de concretizá-la.

Palavras-chave Equipe de Saúde da Família, Integralidade, Interdisciplinaridade, Atenção básica 
Introdução

O Programa Saúde da Família (PSF) se constituiu como uma proposta para mudança do processo de trabalho na atenção básica no Brasil, com o objetivo de qualificar a assistência à saúde da população com base nas diretrizes do Sistema Ú nico deSaúde: descentralização, integralidadeecontrolesocial.

As equipes de saúde da família são compostas por médico, enfermeiro, técnico em enfermagem, agentes comunitários de saúde e odontólogo ${ }^{2}$. 0 PSF foi desenvolvido com o objetivo de estreitar laços de compromisso entre profissionais da saúde, educação, gestores e população usuária dos serviços de saúde. Essa iniciativa apresentou avanços importantes na prestação de serviços, uma vez que vem contribuindo significativamente para a efetivação de mudança no modelo assistencial, com ênfase na promoção de saúde da família ${ }^{1}$.

Os cursos de capacitação em saúde da família no Brasil, na forma deespecialização ou residência, têm sido construídos com caráter multiprofissional, incluindo profissionais como assistentes sociais, farmacêuticos, psicólogos, nutricionistas, fonoaudiólogos, fisioterapeutas, dentre outros. Esses cursos são locus de experiências importantes para o desenvolvimento deuma prática interdisciplinar, que geralmente não recebe a ênfase necessária nos cursos de graduação. Além disso, os programas incentivados pelo M inistério da Saúde, como as residências e especializações multiprofissionais em saúde da família, abrem espaço para novas conquistas na qualificação da assistência à saúde no Brasil. A possibilidade de experienciar o trabalho em equipe multiprofissional e a interdisciplinaridade capacitam os profissionais para a mudança no modelo assistencial, tanto os quejá atuam no serviço público, quanto os que ainda não.

Um dos principaisfatores que dificultam a prática da interdisciplinaridade no trabalho das equipes é a formação dos profissionais de saúde, que prioriza conhecimentos técni cos adquiridos e desconsidera práticas populares da comunidade na qual a equipe é inserida. Além disso, privilegia o trabalho individual em relação ao coletivo, o que prejudica a integração da equipe e a aplicação da prática necessária3.

Conceituar a interdisciplinaridade não étarefa fácil, pois se trata de um assunto vasto e complexo, o que dá margem para múltiplas formas de interpretação. Esta dificuldade acentua-se ainda mais na prática. 0 que ocorre nos serviços de saúde, na sua maioria, são encontros multidisciplinares, em queos profissionais permanecem com suas práticas individuais, distanciando-se do trabalho interdisciplinar ${ }^{4}$.

Segundo Zannon", interdisciplinaridade "são ações conjuntas, integradas e inter-relacionadas, deprofissionais de diferentes procedências quanto à área básica do conhecimento". Gomes ${ }^{3}$ acrescenta que o trabalho interdisciplinar envolve a criatividade, originalidade eflexibilidade frente à diversidade de formas de pensar, frente aos problemas e às suas soluções. 0 autor lembra que na prática interdisciplinar não se preten de uma desvalorização ou negação das especialidades. 0 que se busca é a superação da fragmentação do conhecimento, reconhecendo e respeitando as especificidades de cada área profissional. Para M ei relles ${ }^{4}$, éo diálogo contínuo com outras formas de conhecimento de maneira compartilhada e interativa que facilita os enfrentamentos profissionais e a assistência humanizada e cidadã que contribui para melhorar a compreensão da realidade.

Ultrapassar o âmbito individual e clínico exige mudanças na maneira de atuar e na própria organização do trabal ho edemanda alta complexidade desaberes. Cada profissional precisa desempenhar sua profissão em um processo de trabalho coletivo, cujo resultado deve ser a consequência de um trabal ho que é realizado de forma completa a partir da contribuição específica das diversas áreas profissionais ou de conhecimento ${ }^{6}$.

Para realmente ultrapassar 0 âmbito individual eclínico, é necessário "conhecer e analisar o trabalho, verificando as atribuições específicas e do grupo, na unidade, no domicílio ena comunidade, como também compartilhar conhecimentos e informações"7.

Os conceitos de campo enúcleo são especificados por $\mathrm{Campos}^{8}$ de modo a combinar a necessidade depolivalência eespecialização, edeconciliar autonomia com responsabilidade. "Por Núcleo entender-se-ia o conjunto de saberes e de responsabilidades específicos de cada profissão ou especialidade" [...] "Por Campo, ter-se-iam saberes e responsabilidades comuns e confluentes a várias profissões ou especialidades. Todo o saber básico, por exemplo, sobre o processo de saúde-doença" .

Em todos os níveis de atenção à saúde, percebe-se a necessidade do trabalho interdisciplinar, uma vez que é justamente a partir de tal trabalho que se almeja alcançar uma abordagem integral sobre os fenômenos que interferem na saúde da população. A partir desta abordagem, objetiva-se atingir maior eficiência e eficácia dos programase serviços oferecidos à população. A partir disto, os Conselhos Federais e Regionais de cada categoria profissional vêm se organizando e lutando pela 
inserção de seus trabal hadores nos serviços de saúde pública, o que inclui o Programa Saúde da Família. Isto acontece a partir de movimentos para a conscientização da importância de outros profissionais para a atenção integral da população, através de participação nas conferências de saúde, de mudanças curriculares, entre outros.

0 presente trabalho tem como objetivo principal apontar as principais dificuldades encontradas pela equipe mínima da Estratégia de Saúde da Família (médico, enfermeiro e dentista) para a ação interdisciplinar na atenção básica no que se refere à composição destas equipes. Apresentar-se-ão resultados parciais de um trabalho de conclusão do curso de especialização multiprofissional em saúde da família da Universidade Federal de Santa Catarina, que discute a relação entre integralidade na atenção básica e a composição das equipes de saúde da família, na perspectiva dos profissionais incluídos na equipe mínima do PSF.

\section{M étodo}

A pesquisa foi realizada em um município do sul do Brasil, em centros de saúdee unidades de saúde com equipes de PSF em diferentes bairros, entre os meses de setembro a novembro de 2005. Participaram do estudo quinze profissionais de nível superior, legalmente incluídos na equipe mínima do PSF, ou seja, médicos, enfermeiros e odontólogos. Os dados foram coletados por meio de entrevistas individuais semi-estruturadas, gravadas e transcritas para a análise.

Trata-se de uma pesquisa descritivo-correlacional debaseepistemológica qualitativa, pertinenteà investigação de fenômenos complexos, como as representações, as vivências, as crenças, os valores e os significados ${ }^{9}$. A pesquisa foi realizada de acordo com as normas da Resolução 196/96 do Conselho Nacional de Saúde, sendo que todos os participantes foram esclarecidos sobre os objetivos e o método, mediante a leitura e assinatura do termo deconsentimento livre eesclarecido. A pesquisa não apresentou riscos para os participantes, foiIhes garantido o sigilo e também o retorno sobre os resultados da mesma.

\section{Resultados ediscussão}

Perfil dos profissionais pesquisados

A Tabela 1 mostra a caracterização dos participantes da pesquisa quanto à idade, sexo, área de formação e especialização. D os profissionais entre vistados (15), 67\% eram do sexo feminino, $46,7 \%$ eram médicos, $33,3 \%$, enfermeiras e $20 \%$, odontólogos. Apenas $20 \%$ dos participantes entrevistados não possuíam especialização. A maioria dos entrevistados possuía alguma formação na área da saúde pública (46,8\%). A idade dos entrevistados variou de 23 a 60 anos, sendo que $40 \%$ destes possuíam até 30 anos. 0 tempo de atuação e participação na atual equipe de Saúde da Família variou bastante: $26,6 \%$ estavam na equipe há menos de seis meses, $46,8 \%$ atuavam na mesma equipe em um período de um ano a dois anos, enquanto que $26,6 \%$ atuavam em um intervalo de três a cinco anos.

\section{Trabalho em equipe no PSF}

As reflexões sobreo trabal ho em equipeno PSF evidenciaram a falta de clareza, por parte dos profissionais de saúde, em discernir núcleo e campo de competência, eas fronteiras entre seu núcleo eo dos demais, principalmente no que concerneà realização de grupos. 0 trabalho com grupos nas unidades e centros de saúde é uma tarefa prevista no PSF, ou seja, faz parte do campo de competên-

\begin{tabular}{ll}
\hline Tabela 1. Caracterização dos participantes. \\
\hline Dados dos participantes & \\
\hline Categorias profissionais & \\
$\quad$ M édicos & 7 \\
Enfermeiras & 5 \\
Odontólogos & 3 \\
Pós-graduação & \\
$\quad$ Especialização em Saúde Pública & 7 \\
Especialização em outras áreas & 6 \\
Apenas graduação & 3 \\
Idade & \\
Até 30 anos & 6 \\
De 31 a 50 anos & 5 \\
Acima de 51 anos & 4 \\
Sexo & \\
Homens & 5 \\
Mulheres & 10 \\
Tempo de atuação profissional & \\
Até 1 ano & 1 \\
De 1 ano a 10 anos & 7 \\
De 11 anos a 20 anos & 1 \\
De 21 a 30 anos & 6 \\
Tempo de atuação na equipe de PSF atual & \\
Até 6 meses & \\
De 7 meses a 2 anos & 4 \\
De 3 anos a 5 anos & 7 \\
\hline
\end{tabular}


cia, e cada profissional pode contribuir de acordo com o seu núcleo de competência. A fala a seguir retrata a opinião de um dos participantes da pesquisa quanto ao trabalho nos grupos denominados "grupos terapêuticos": Como éque a gente trabalha com grupos terapêuticos e não tem psicólogo? Qual é a formação que eu tenho pra fazer grupo terapêutico? (Entrevista 03)

Com esta fala, o entrevistado demonstra a necessidade e a falta do profissional psicólogo, especialmente em atividades para as quais está capacitado. Demonstra também a angústia pela falta de preparo dos profissionais da equipe para tais atividades.

Silva e Trad 6 mencionam que no PSF é possível perceber a existência de uma tensão entre a fragmentação e a integração do processo de trabalho, havendo, deste modo, o risco dos profissionais se isolarem em seus "núcleos de competência”.

É preciso ainda observar que os profissionais que trabalham na atenção básica deveriam compreender e agir sobre os determinantes do processo saúde/doença. Isto implicaria realizar uma união de saberes a serem utilizados na definição dos cuidados dos indivíduos e famílias; no entanto, as práticas profissionais estabelecidas pelo modelo flexneriano não destacam tal percepção, limitando o cuidado às práticas pontuais e curativas ${ }^{10}$.

As considerações levantadas por $\mathrm{Gi}^{10}{ }^{10}$, principalmente quanto às práticas pontuais, curativas e com a ausência de união de saberes, podem ser observadas no depoimento abaixo: $\mathrm{N}$ a verdade no nosso dia-a-dia, a gente faz o que pode, como eu te falei, deacordo com os recursos que a gentetem, com a equipe que a gente tem, a gente faz o que pode, tá mais em cada profissional fazendo assim da sua forma. $\mathrm{N}$ a verdade, eu penso que a gente não está conseguindo atender esse ser humano como um todo, não. Eu não sei mais o que dizer... [risos]. (Entrevista 12)

Um estudo realizado sobre o consenso e diferenças em equipes do PSF mostrou que competências e responsabilidades foram assuntos que promoveram segmentação entre grupos e subgrupos na equipe de saúde, isto porque a equipe não se auto-considera um coletivo organizado para a produção de ações de saúde. Ainda falta a eles um conceito ampliado de trabal ho, que leve em conta tanto 0 anseio e 0 interesse do agente produtor, quanto as necessidades sociais ${ }^{11}$. Deve-se procurar, nos programas de saúde coletiva, a organização de novas propostas de ação conjunta voltadas para resolver problemas importantes de cada território, agregando contribuições de diversas áreas técnicas, cooperando para que as equipes de saúde possam estar capacitadas a tratar as situações e problemas de forma integral ${ }^{12}$.

Alcançar a atenção integral implica a ampliação da base conceitual de cada profissional de saúde na construção da compreensão do trabal ho em saúde, isto somado ao reconhecimento da limitação da ação de um único profissional para atender as necessidades de saúde dos indivíduos e da comunidade. Para tanto, além da ampliação da base conceitual, também énecessária a configuração de equipes para a ação interdisciplinar, visando ao maior vigor de cada ação planejada e executada ${ }^{13}$.

Atividades desempenhadas

pelos profissionais da equipe mínima

Os entrevistados relataram realizar diversas atividades que não são específicas de suas profissões. Entre as tarefas que desempenham frequentemente, apesar deultrapassarem os limites de suas competências, citaram a dispensação de medicamentos - ação relativa ao núcleo de competência do farmacêutico; a coordenação de grupos terapêuticos e aconselhamento, incluindo a tentativa deintervir nos aspectos emocionais associados aos sintomas físicos - atribuição do núcleo de competência do psicólogo.

0 fragmento a seguir expõe a abordagem de um dos profissionais relacionada ao núcleo de competência do psicólogo: Às vezes, por exemplo, mesinto um pouco psicóloga, por queàs vezesa gente tem mesmo que abordar outros aspectos que a genteda medicina não tá preparado, né? 0 lado emocional, se leva aquela pessoa a ter sintomas, assim, não que eu vá fazer psicoterapia, mas é preciso entender melhor. (Entrevista 04)

Os entrevistados ainda referiram realizar orientação alimentar, através de "dicas" sobrealimentação, principalmente para os pacientes hipertensos e/ou diabéticos - atribuição designada ao núcleo de competência do nutricionista. Isto podeser observado na fala de um dos participantes da pesquisa: A gente sente dificuldade de encaminhar, mas de forma geral a gente acaba dando dicas e falando bastante da alimentação saudável, às vezes tem sobrepeso. (Entrevista 04)

A realização deatividades referentes ao núcleo de competência do assistente social por parte dos profissionais de saúde do PSF também foi evidenciada dentre os relatos dos entrevistados: U ma coisa quea gentefaz muito éa parteda assistência social, no posto desaúde. Quea gentenão tem na equipeuma assistentesocial, seria fundamental ter assistentesocial, né? E a gente acaba abraçando muito isso. Tanto o médico, quanto 0 enfermeiro, geralmente. (Entrevista 05) 
As enfermeiras entrevistadas relataram que executam funções de auxiliares técnicos administrativos, como marcação de consultas, exames e tarefas relacionadas à recepção da unidade. Os odontólogos foram os profissionais que mais expuseram a realização de tarefas que deveriam ser executadas pelostécnicos, umavez quedificilmentecontam com os serviços do auxiliar de consultório dentário (ACD). Enfatizaram a dificuldade durante suas atividades diárias devido à ausência do profissional responsável pela assepsia elimpeza dos instrumentos e do próprio consultório odontológico.

Quando questionados sobre as situações em que desempenham atividades que estão além dos limites de seu núcleo de competência, os entrevistados mencionaram que costumam realizar tais tarefas mediante a falta de profissionais e citaram casos específicos de atuação, como em situações de violência familiar, desemprego, falta de moradia e pobreza. Também justificaram tal atitude, esclarecendo que se não fizerem o que está além de suas atribuições, ocorrem reclamações dos usuários. Diante da demanda dos usuários, que ultrapassa tanto o núcleo quanto o campo de competência dos profissionais da equipe mínima, observou-se a ambivalência dos participantes da pesquisa em se autorizar a atender tal demanda e se julgar competente ou não para isso.

Com relação às dificuldades dos profissionais da equipe mínima em decorrência da falta dos demais profissionais, foi observado que as respostas dividem-se entreos entrevistadosinseridos em centros ou unidades de saú de com equipe ampliada, e entre os inseridos numa unidade de saúde com equipe mínima do PSF. Esta fragmentação ocorre devido às diferentes necessidades de cada equipe, pois em equipes ampliadas há uma maior oferta de algumas especialidades médicas, enquanto que a equipe mínima sofre uma sobrecarga e mostra sentir mais dificuldades inclusive na realização do acolhimento.

Para Gomes ${ }^{3}$, o saber interdisciplinar dá condições ao profissional de saúde de perceber o homem como um todo, necessitando, assim, de uma visão mais ampla, que ultrapasse a sua especificidade profissional, e que caminhe na direção da compreensão das implicações sociais decorrentes de sua prática. Esta mudança acarreta o fim da hegemonia de alguns saberes sobre outros, principalmente do saber médico, tão valorizado na concepção biológica do processo saúde-doença.

Em seu estudo, Peduzzi ${ }^{14}$ observou que 0 trabalho em equipe requer que os profissionais das diferentes áreas conheçam, respeitem e valorizem o trabalho dos demais, pois, dessa maneira, pode- rão identificar e compreender os aspectos das necessidades de saúde que melhor podem ser assistidos ou cuidados pelo agente de outra área, encaminhando para outros profissionais, quando necessário. Desta forma, poderão criar um conjunto de ações cujo conteúdo e objetivos sejam do conhecimento de todos os envolvidos. 0 autor afirma ainda que um dos aspectos centrais na configuração do trabalho em equipe é conhecer o trabalho do outros. Este trabalho em equipetorna-se possível com base na convivência, no relacionamento e na troca de informações.

Dificuldades dos profissionais

em diferentes equipes

Profissionais que atuam em centros de saúde e unidades com equipe ampliada

Um centro ou unidadelocal desaúdecom equipe ampliada contém em seu quadro funcional um ou mais profissionais de nível superior, além daqueles quefazem parte da equipe mínima desaúde (médico, dentista e enfermeiro). Os profissionais inseridos em unidades como estas relataram que, quando há na unidade outros profissionais para quem possam encaminhar, mesmo que estes não sejam exclusivos daunidade de saúde, enem sejam integrantes formais da equipe de PSF, éo suficiente para suprir a necessidade de atendimento à população. Muitos dos entrevistados sugeriram que apenas um destes profissionais poderia atender duas ou mais equipes de PSF, o que sugere um desconhecimento da complexidade do trabalho de outros profissionais. Assim, não seriam necessários em período integral na unidade, como exemplificado na fala deste profissional: Poderia ser até assim, ó: um psicólogo pra cada cinco postos de saúde. Então alguém da farmácia, poderia ser quenem 0 psicólogo, não precisa ser um direto assim. M as seele ficar aqui umas duas vezes por semana, e em outros postos. (Entrevista 03)

A experiênciainterdisciplinar possibilita o contato com diferentes referenciais e estruturas, enriquecendo o saber e trazendo novas formas de cooperação e comunicação entre os profissionais e entre estes e o usuário. N esta prática, o desafio de lidar com as próprias diferenças e com as diferenças dos outros está presente a todo o instante, 0 que traz, em vez de barreiras, estímulo eriqueza ao trabalho realizado 3 .

Profissionais que atuam em unidades com equipe mínima

Já os profissionais inseridos em unidades que contêm em seu quadro de funcionários apenas a 
equipe mínima do PSF mostraram sentir mais dificuldades, pois a falta de outros profissionais gera sobrecarga e dificulta o trabalho na unidade de saúde. Alguns deles referiram-se ao acolhimento como algo que, também pela falta de profissionais, não é feito na unidade. Profissionais como o nutricionista eo farmacêutico foram citados como degrande importância na atividade de acol himento: Pela falta do profissional, a gente acaba fazendo muito. E não tem preparo pra isso, às vezes, meio que acaba atendendo. Então, quanto o resto, né, no posto a gente faz tudo que precisa na realidade. $N$ ão tem funcionário na farmácia, tu vai lá e ajuda a atender na farmácia. Não tem funcionário, tá ocupado fazendo outra coisa, tá precisando de um curativo, tu vai lá e acaba fazendo, né. A té mesmo na marcação de consulta, às vezes o funcionário que faz, não tá, tu dá uma força, tu vai lá e acaba ajudando. A genteassim, como não éuma equipemuito grande, todo se dá bem, acaba sempre trabalhando junto. (Entrevista 05)

Sobre a importância de uma equipe interdisciplinar, M eirelles ${ }^{4}$ refere que a realidade de hoje, contendo uma pluralidade denecessidades, especificidades etransformações, requer diferentes abordagens com múltiplas teorias para explicá-la e enfrentar os problemas que se apresentam. A saúde, como um processo dinâmico e complexo, inserido nesta realidade, demanda reflexõesinterdisciplinares. N este sentido, constatou-se que, em unidades locais de saúde que contam apenas com os profissionais da equipe mínima, capacitados sobretudo para lidar com os aspectos orgânicos, o usuário geralmentenão podeser atendido em todas as suas necessidades, pois estas ultrapassam a concepção biologicista de saúde, abrangendo todas as áreas da vida da pessoa que procura o atendimento. Cabe ressaltar que a maioria dos entrevistados mostrou ter uma concepção ampliada de saúde, trazendo preocupações e colocações acerca dos contextos cultural, social, emocional e econômico dos usuários, inclusive associando-os ao fator biomédico.

O saber interdisciplinar dá condições ao profissional de saúde de perceber o homem como um todo, necessitando, assim, de uma visão mais ampla, que ultrapasse a sua especificidade profissional, e que caminhe na direção da compreensão das implicações sociais decorrentes de sua prática. Esta mudança acarreta o fim da hegemonia de alguns saberes sobre outros, principalmente do saber médico, tão valorizado na concepção biológica do processo saúde-doença ${ }^{3}$.
Inclusão de outros profissionais na equipe mínima do PSF

A análise da necessidade da inclusão de outros profissionais na equipe mínima do PSF foi caracterizada pelo ponto de vista dosintegrantes da equipe e pelo ponto de vista dos usuários, a partir dos relatos dos participantes da pesquisa.

Quanto aos profissionais entrevistados, alguns relataram a necessidade de assessoria de profissionais de outras categorias, para capacitá-los a lidar com seus pacientes de maneira mais ampla, com os conhecimentos de outras áreas. Desta forma, 0 profissional não atuaria diretamente com a população, exceto com a função de instruir aquele já inserido na equipe do PSF. Mais uma vez, os relatos apontaram para a não necessidade destes outros profissionais como exclusivos de uma equipe de PSF, mas sim como pertencentes a algumas unidades de saúde.

Alguns profissionais relataram a necessidade de outros profissionais para trabalhos de grupos em que a equipe esteja integrada e as atividades planejadas: Então se tivesse esse outro profissional que pudesse estar coordenando esse grupo, tá integrando a equipe e absorvendo uma parte do bolo. A gente poderia imaginar a equi pe de saúde da família como um bolo, tem momento que nós precisamos nos unir, mas em alguns desses momentos cada um poderia ficar responsável por uma fatiazinha desse bolo, alguém vai trabalhar mais com a gestante, um outro coordenaria um grupo de hipertensos, mas no dia-a-dia a equipe teria que se unir. (Entrevista 11)

$M$ achado afirma ser incompreensível que, na atualidade, as equipes de saúde não incluam outros profissi onais das diversas áreas da saúde como terapeutas ocupacionais, fisioterapeutas, psicólogos, nutricionistas e outros. De acordo com este autor, a saúde é um campo inesgotável de conhecimento e de prática profissional e incorpora também novas áreas do conhecimento, envolvendo por vezes na equipe a presença de profissionais na saúde até então de áreas inimagináveis, tais como engenharia, serviço social, economia, sociologia, arquitetura, pedagogia, entre outras ${ }^{15}$.

0 profissional quevem de uma formação cientificista écarente deuma compreensão global do processo saúde doença. Por esta causa, tende a desconhecer e desvalorizar o conhecimento e a prática de outros profissionais, ficando restrito à sua especificidade. Todos saem perdendo neste processo: tanto 0 profissional que não divide 0 que sabe, como 0 profissional que não percebe a importância de seu colega. Cabe acrescentar que o usuário da unidade desaúdeéo principal afetado diante detal situação ${ }^{3}$. 
Algumas categorias profissionais foram citadas espontaneamente duranteas entrevistas, como necessárias à equipe de saúde do profissional entrevistado. 0 psicólogo apareceu na maioria dos relatos ( 12 vezes), seguido do assistente social (9), do nutricionista (6), do fisioterapeuta (5), educador físico (4), farmacêutico (4), terapeuta ocupacional (2) fonoaudiólogo (2) e bioquímico (1). Também espontaneamente, foram citados profissionais que não pertencem ao ramo da saúde, como o musicoterapeuta (1) e o educador infantil (1). Os profissionais também trouxeram a necessidade de encaminhamentos mais eficazes na alta complexidade, ou seja, manifestaram a carência de especialistas médicos em outras instituições, para onde se possa encaminhar os casos específicos.

Quanto aos usuários, os profissionais entrevistados responderam que em geral estes não solicitam outros profissionais, com exceção de um profissional (Entrevista 04), que relatou pedirem atendimento com psicólogo, nutricionista e fisioterapeuta. 0 restante disse que os usuários costumam reclamar da falta de dentistas e de especialistas mé dicos, como cardiologista, neurologista, ginecologista, entre outros, e também da falta e demora na realização de exames. 0 relato a seguir, feito por um profissional, ilustra a crença de que 0 usuário ainda está fixado ao modelo médico-centrado, no qual este é o único profissional necessário: Não, porque pra eles tá bom, chegaram até mim! Eu é que preciso dos outros. Se eles vêm pra mim, pra eles tá jóia, conseguiram, chegaram ali. (Entrevista 03)

Nos serviços ambulatoriais, a demanda de profissionais não-médicos normalmenteégerada pelo médico. Através das consultas, o paciente é encaminhado aos outros profissionais. 0 autor ainda menciona a existência da necessidade de atender uma rotina de atendimento das ações educativas, ações preventivas, ações de atenção a demandas específicas de caráter social e/ou psicológico eações de assistência médica individual, entre outras ${ }^{14}$.

\section{Possibilidades de inclusão}

Segundo Gomes ${ }^{3}$, ésignificante a diferença entre as expectativas, valores e linguagem dos profissionais de saúde e da população, o que traz grandes dificuldades de comunicação entreeles. 0 próprio autor propõe a solução para o impasse: a participação comunitária, ou seja, a população deve participar de todas as etapas das atividades de saúde, desde o planejamento, passando pela operacionalização até a avaliação do processo. Além disso, a inclusão de outros profissionais nas equipes de PSF depende principalmente de ações educativas dos profissionais já inseridos, que assim mostrariam à população a necessidade de outras categorias profissionais sara um atendimento integral.

Muitas vezes o usuário sabe que tem uma necessidade, mas não identifica ou desconhece que profissional poderia melhor atendêlo. Ele procura os profissionais que estão ao seu alcance na unidade de saúde e seu objetivo é ter o seu problema solucionado, de forma imediata, mesmo que temporariamente. Se o médico, a enfermeira ou o dentista tentam sanar uma necessidade que vá muito além deseu núcleo decompetência, seja emocional, alimentar, social ou outra, por qualquer razão que tenha para fazer isto, o usuário pode sentir-se satisfeito, sem dispor da informação sobre a existência de outros profissionais capacitados para atendê-lo naquela necessidade eque provavelmentedariam um rumo mais eficaz e adequado a esta demanda. N este sentido, ficou claro em várias entrevistas que os profissionais da equipe de saúde do PSF, "tapam os buracos" da falta de outros profissionais, evitando assim que a demanda apareça.

Quando perguntados sobre as discussões e ações feitas para a inclusão de outros profissionais na equipe de saúde, a resposta foi quase unânime: não há discussão formal sobre o assunto, nem tampouco ações que viabilizem a contratação de assistentes sociais, psicólogos, nutricionistas, farmacêuticos, entre outros. As razões para esta falta vão desde a descrença no investimento do governo, atéa necessidade demaisfuncionários, denível técnico e superior, daquelas profissões já inseridas na equipe mínima do PSF. Enfim, todos os entrevistados reconhecem a importância das outras categorias profissionais e a sua necessidade dentro das unidades de saúde, porém pouco se faz para informar o usuário, a equipe de saúde e a população em geral sobre 0 assunto.

Em um estudo realizado por Conill ${ }^{16}$ no PSF de Florianópolis, foi identificado como resultado mais relevante os problemas no acesso, resultantes da insuficiência de recursos humanos, eas dificuldades na referência, apontando assim como principais ações de mudanças a serem realizadas a contratação de profissionais e mudanças na estrutura física com maior oferta de serviços. 0 trabaIho mostrou também que o PSF em Florianópolis está adequado no que se refere à sua estrutura físi$\mathrm{ca}$, área e equipamentos. É inadequado quanto ao item recursos humanos, medido pela relação número de equipes/famílias, para a qual está subdimensionado, e moderadamente adequado quanto à sua capacitação. 


\section{Consideraçõesfinais}

As atribuições das equipes de Saúde da Família são bastante amplas e têm como principais objetivos proporcionar uma atenção integral às famílias, identificar os problemas de saúde, incentivar ações comunitárias, bem como estimular e desenvolver a participação da população local na solução de seus problemas e no exercício do controle social sobre os serviços que recebe. Além dessas atribuições, o PSF exige novos conhecimentos de suas equipes euma perspectiva integrada na análise dos problemas e no encaminhamento das soluções. 0 trabalho em PSF propõe também a organização de relações horizontaisno interior das equipes, com o reconhecimento da competência de cada membro e a busca através do diálogo, a definição de uma ação conjunta e não apenas justaposta de todos os integrantes ${ }^{17}$.

Além disso, o contato dos membros da equipe mínima com as demandas colocam as equipes e seus trabalhadores diante da impotência em dar respostas por meio apenas dos procedimentos técnicos rotineiros, fragmentadores e niveladores e perante a complexidade do objeto da saúde, pois estas necessidades ultrapassam o âmbito para o qual os trabalhadores foram tradicionalmentepre parados: o corpo biológico como objeto de trabaIho ea centralização das ações nos atos médicos ${ }^{18,19}$.

Pode-se sugerir que, ao executar funções que não Ihes cabem especificamente, a equipe mínima está contribuindo para aumentar a opacidade a respeito das limitações que sua atual composição acarreta para a população. Além disso, é importante considerar que este fato fomenta a medicalização histórica da sociedade, que vê na atenção curativa biomédica e especializada a solução para todos os seus males existenciais, incluídos no processo saúde doença. Isto foi evidenciado na referência dos participantes desta pesquisa à demanda da comunidade por mais médicos especialistas, que já fazem parte de seu cotidiano e detêm a legitimidade do saber sobre a saúde e a doença.

Desta forma, a inclusão de outros profissionais nas equipes de PSF dependeria principalmente de ações educativas por parte daqueles já inseridos. Estes mostrariam à população a necessidade de outras categorias para um atendimento integral. Integralidade su põe compartilhar saberes na prática cotidiana. M as não se caracteriza pela substituição destes saberes, pois esta substituição implica privar os usuários de uma atenção profissional qualificada para atender a todas as suas necessidades de forma resolutiva. Cabe refletir sobre a avaliação da demanda dos usuários pelos profissionais.
Os gestores, por sua vez, também não serão confrontados com essa necessidade e continuarão a perpetuar o modelo hegemônico vigente. Além disso, o trabalho da equipe de Saúde da Família necessita de uma aproximação das demandas dos usuários, proporcionando assim uma flexibilidade que atenda a essas necessidades e que possa ser completada com a inclusão de outros profissionais para uma assistência integral ao paciente. É inevitável, então, refletir sobre o papel dos gestores e dos supervisores de equipes de Saúde da Família na incorporação de outros profissionais, que possam atender a estas necessidades. Ainda, no âmbito da gestão, embora as políticas públicas tenham um enfoque na integralidade ena interdisciplinaridade como formas de qualificar a assistência em saúde, paradoxalmente, iniciativas para esta ampliação da equipe mínima não são prioritárias.

Embora não tenham sido foco deste estudo, profissionais de outras áreas do conhecimento também contribuiriam como membros das equipes de saúde, como por exemplo o engenheiro sanitarista, o administrador, os educadores, dentre outros. É relevante destacar que muitas possibilidades de contribuição de outros profissionais no PSF foram mencionadas pelos entrevistados. Além disso, as dificuldades no processo de trabal ho estiveram relacionadas às limitações do seu núcleo de competência, e eles relataram diversas características da demanda que seriam melhores atendidas se houvesse uma equipe efetivamente multiprofissional einterdisciplinar.

Cada especialidade precisa ultrapassar sua área deformação e competência, evidenciando seus próprios limites e buscando a contribuição de outras disciplinas, respeitando o território de cada campo de conhecimento e, ainda, distinguindo os pontos que os unem e os que diferenciam. Essa é a condição necessária para detectar as áreas em que se possam estabelecer as conexões possívei ${ }^{20}$.

Por fim, não se pretende esgotar a questão da composição das equipes de PSF, mas sim despertar a discussão sobre as implicações da composição atual das equipes em relação ao processo de trabaIho eàs demandas apresentadas pela população. $A$ elaboração deste trabalho durante a realização do curso de especialização multiprofissional em saúde da família possibilitou o compartilhar de experiências, contribuindo na construção de nossa trajetória profissional tanto para conhecer melhor as especificidades do fazer decada um dos profissionais, quanto para debater questões que ultrapassam a dimensão técnica da assistência em saúde e que são estruturais na organização e funcionamento dos serviços de saúde atual mente no Brasil. 


\section{Colaboradores}

G Loch-Neckel, G Seemann, HB Eidt e M M Rabuske participaram da idealização, delineamento de objeto de estudo, desenho da metodologia, coleta e análise dos dados e redação do artigo. participou da idealização, delineamento de objeto de estudo, desenho da metodologia, coleta e análise dos dados. MA Crepaldi participou do delineamento de objeto de estudo e do desenho da metodologia e foi responsável pela coordenação, orientação e acompanhamento do trabalho de campo e revisão critica do artigo.

\section{Referências}

1. Brasil. Ministério da Saúde. Saúde da Família: uma estratégia de organização dos serviços de saúde. Brasília: M inistério da Saúde; 1996.

2. Brasil. M inistério da Saúde. Portaria no 1.444/GM , 28 de dezembro de 2000. Estabelece incentivo financeiro para a reorganização da atenção à saúde bucal prestada nos municípios por meio do Programa de Saúde da Família. Diário Oficial da U nião 2000; 29 dez.

3. Gomes DCR, organizador. Equipe de saúde: 0 desafio da integração. Uberlândia: Editora da U niversidade Federal de Uberlândia; 1997.

4. M eirelles BHS. Viver saudável em tempos de AIDS: a complexidade e a interdisciplinaridade no contexto de prevenção da infecção pelo HIV [tese]. Florianópolis (SC): Programa de Pós-Graduação em Enfermagem, Universidade Federal de Santa Catarina; 2003.

5. Zannon CM AC. Desafios à psicologia na instituição de saúde. Psicologia: Ciência Profissão 1994; 13:16-21.

6. Silva IZQJ, Trad LAB. 0 trabalho em equipe no PSF: investigando a articulação técnica e a interação entre os profissionais. Interface (Botucatu) 2004/2005; 9:25-38.

7. Brasil. Ministério da Saúde. Secretaria de Políticas de Saúde. Departamento de Atenção Básica. M anual para a Organização da Atenção Básica. Brasília: Ministério da Saúde; 2001.

8. Campos GWS. Subjetividade e administração de pessoal: considerações sobre modos de gerenciar o trabalho em equipes de saúde. In: M erhy EE; Onocko $R$, organizadores. Agir em equipes de saúde: um desafio para o público. São Paulo: Hucitec; Buenos Aires: Lugar Editorial; 1997. p. 229-265.

9. M inayo MC, Sanches O. Quantitativo-qualitativo: oposição ou complementariedade? Cad Saude Publica 1993; 9(3):239-262.

10. Gil CRR. Formação de Recursos Humanos em saúde da família: paradoxos e perspectivas. Cad Saude Publica 2005; 21:490-498.

11. Pedrosa JIS, Teles JBM. Consenso e diferenças em equipes do Programa Saúde da Família. Rev. Saude Publica 2001; 35:303-311.

12. Campos CEA. O desafio da integralidade segundo as perspectivas da vigilância da saúde e da saúde da família. Cien Saude Colet 2003; 8:569-584.

13. Ceccim RB, Feuerwerker LCM. Mudança na graduação das profissões de saúde sob o eixo da integralidade. Cad Saude Publica 2004; 20:1400-1410.

14. Peduzzi M. Equipe multiprofissional de saúde: a interface entre trabalho e interação [tese]. Campinas (SP): Faculdade de Ciências M édicas, Universidade Estadual de Campinas; 1998.

15. M achado $\mathrm{MH}$. Mercado de trabalho em saúde. In: Falcão A, Santos N eto PM, Costa PS, Belisário AS, organizadores. Observatório de recursos humanos em saúde no Brasil: estudos e análises. Rio de Janeiro: Fiocruz; 2003, p. 227-248.

16. Conill EM. Políticas de atenção primária e reformas sanitárias: discutindo a avaliação a partir da análise do Programa Saúde da Família em Florianópolis, Santa Catarina, Brasil, 1994-2000. Cad Saude Publica 2002; 18 (Supl.):191-202.

17. M arsiglia RM G. Instituições de ensino e o Programa de Saúde da Família: o que mudou? Rev Bras Saúde Família 2003/2004; 7:30-41. 
18. Fortuna CM, Mishima SM, M atumoto S, Pereira MJB. Trabalho de equipe no programa de saúde da família: Reflexões a partir de conceitos do processo grupal e de grupos operativos. Rev Latino-am enfermagem 2005; 13:262-268.

19. M atumoto S, Fortuna CM, M ishima SM, Pereira MJB Domingos NAM. Supervisão de equipes no Programa de Saúde da Família: reflexões acerca do desafio da produção de cuidados. Interface (Botucatu) 2004/ 2005, 9: 9-24.

20. Siqueira HSG, Pereira MA. A interdisciplinaridade como superação da fragmentação. Caderno de Pesquisa [periódico na Internet].1995 Set [acessado 2007 jul 15]; 68: [cerca de 2 p.]. Disponível em: http:// www.angelfire.com/sk/holgonsi/interdiscip3.htm

Artigo apresentado em 25/08/2007

Aprovado em 04/12/2007

Versão final apresentada em 18/12/2007 